ISSN 1518-3483

Licenciado sob uma Licença Creative Commons

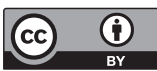

\title{
A pesquisa na formação e no trabalho dos professores da educação básica
}

\author{
The research on teacher's training and \\ work on elementary school
}

\section{Kátia Augusta Curado Pinheiro Cordeiro da Silva ${ }^{[a]}$, Sandra Valéria Limonta ${ }^{[b]}$}

[a] Doutora em Educação pela Universidade Federal de Goiás (UFG), professora adjunta do Programa de Pós-graduação em Educação da Universidade de Brasília (UnB), Brasília, DF - Brasil, e-mail: katiacurado@unb.com.br

[b] Doutora em Educação pela Universidade Federal de Goiás (UFG), professora adjunta da Faculdade de Educação da Universidade Federal de Goiás (UFG), Goiânia, GO - Brasil, e-mail: sandralimonta@gmail.com

\section{Resumo}

O presente artigo apresenta uma análise da pesquisa na formação e no trabalho dos professores que atuam na educação básica pública no Estado de Goiás e no Distrito Federal. Utilizamos como perspectiva metodológica, o materialismo histórico-dialético, tendo como referência A discussão que trazemos é fruto da análise de dados de uma investigação já concluída, realizada no período de 2007 a 2009, sobre a concepção de pesquisa dos professores da educação básica que possuem formação stricto sensu e de uma outra 
investigação que encontra-se em andamento, iniciada em 2010 e que tem como objeto a formação e a atuação de pedagogas(os) em espaços escolares e não escolares. Os resultados apontam que os professores com formação stricto sensu vivem um processo de proletarização no trabalho e que desejam realizar pesquisas, mas não têm condições estruturais para desenvolvê-las, demandando a necessidade de se investir na carreira docente como uma política de profissionalização e valorização.

Palavras-chave: Formação de professores. Pesquisa. Trabalho docente.

\section{Abstract}

This article presents an analysis of research on teacher's work from elementary public schools in Goiás state and in the Federal District. We use the dialectic and historical materialism as methodological perspective. We bring the discussion of data analysis from a research already completed, conducted in the period from 2007 to 2009, on the research conceptions of elementary school teachers that have a master or a doctor degree. We also present some results from another ongoing research which began in 2010, whose theme is the training for research on the Pedagogy course. The results indicate that teachers with master or doctor degree experience a process of impoverishment of teaching, still wishing to do research, but with no structural conditions to develop them, what makes it necessary to invest in teaching career as a valuation and professionalization policy.

Keywords: Teacher's training. Research. Teacher's work.

\section{Introdução}

Este artigo apresenta uma reflexão sobre a pesquisa na formação e no trabalho de professores da educação básica a partir de duas investigações realizadas pelo Grupo de Estudos e Pesquisas sobre a Formação e a Atuação de Professores e Pedagogos (GEPFAPe), composto por professores e alunos da graduação e da pós-graduação das faculdades de educação da Universidade de Brasília e da Universidade Federal de Goiás. 
A discussão que trazemos é fruto da análise de dados de uma investigação já concluída, realizada no período de 2007 a 2009, sobre a concepção de pesquisa dos professores da educação básica que possuem formação stricto sensu e de uma outra investigação que encontra-se em andamento, iniciada em 2010 e que tem como objeto a formação e a atuação de pedagogas(os) em espaços escolares e não escolares, da qual já possuímos dados para discutir o papel da pesquisa nesta formação e atuação.

O principal objetivo das investigações é identificar as concepções dos professores da educação básica sobre pesquisa e mapear as pesquisas que são realizadas por estes. Partimos de um problema que consideramos fundamental neste momento histórico em que se enfatiza, nas políticas e programas para a educação básica, a necessidade de melhorar a formação dos professores brasileiros: Qual é o papel da pesquisa na formação e no trabalho dos professores?

A concepção de pesquisa que norteia nossas investigações no GEPFAPe é sintetizada por Marx (1983, p. 20): “[...] a pesquisa tem que captar detalhadamente a matéria, analisar suas várias formas de evolução e rastrear a sua conexão íntima". Para nós, o professor necessita, pela natureza do seu trabalho, passar por um processo formativo de alto nível que articule ciência, ética, técnica e estética. Nesse sentido, a pesquisa é um princípio formativo e um conhecimento pedagógico indispensável na construção de um trabalho docente de qualidade.

Em nossas investigações sobre a formação e o trabalho dos professores temos nos posicionado criticamente quanto à concepção de pesquisa que atualmente tem dominado a discussão sobre pesquisa na formação e na prática dos professores, epistemologia conhecida entre nós como "professor-reflexivo e/ou professor-pesquisador". O trabalho investigativo que realizamos até aqui nos permite apontar fragilidades nessa concepção de pesquisa, que no nosso entendimento não rompe com a dissociação entre teoria e prática, pelo contrário, aumenta a distância entre a formação e o trabalho dos professores, entre o que se passa na escola e a produção de conhecimentos científicos sobre a educação. "Não se trata mais de conhecer a realidade, de intervir sobre ela, mas tão somente de 
perguntar como ocupar-se dela melhor, como alcançar mais eficazmente os objetivos" (MORAES, 2003, p. 56).

Os resultados da investigação sobre a concepção de pesquisa dos professores da educação básica com formação stricto sensu, realizada no período de 2007 a 2009 em Goiânia, indicam que os professores possuem três concepções de pesquisa que se justapõem e se interpenetram:

a) referem-se à atividade investigativa com uma perspectiva acadêmica, identificada com a pesquisa que se realiza em cursos de pós-graduação stricto sensu;

b) como caminho para a solução de um problema vivenciado numa situação de sala de aula;

c) como o estudo de diferentes temáticas que os interessam.

Outra concepção de pesquisa importante que emergiu nesta investigação é que os professores identificam certas atividades inerentes ao trabalho docente como estudar um conteúdo, planejar as aulas e trocar experiências com outros colegas em reuniões como pesquisa. Quando questionados se fazem pesquisa e qual tipo de pesquisa realizam, respondem que pesquisam informações sobre conteúdos que deverão ser ensinados aos alunos, novas metodologias, ideias e atividades que podem auxiliá-los em aula, recursos e materiais didáticos. Descrevem também como pesquisa atividades de observação dos alunos e estudos sobre dificuldades de aprendizagem, indisciplina, inclusão e outros temas, geralmente realizados de forma individual e sem registro, buscando a resolução de problemas enfrentados em sala de aula.

Os sujeitos dessa pesquisa, como já mencionamos, são professores que realizaram cursos de mestrado e doutorado, mas são poucos os que relacionam a pesquisa realizada na formação stricto sensu com suas atividades docentes. A maioria afirma ter realizado sua investigação visando à especialização em sua área de conhecimento e não a partir da prática pedagógica ou de alguma dificuldade enfrentada na escola. Por outro lado, afirmam que a realização do mestrado e/ou do doutorado proporcionou uma 
visão mais ampla e crítica sobre a educação, o que de certa forma acaba contribuindo para mudanças no trabalho pedagógico realizado na escola.

A segunda investigação tem como objeto a formação e a atuação de pedagogas(os) e ainda está em andamento, tendo sido iniciada em 2010. Nesta pesquisa, realizada junto a pedagogas(os) que estão atuando em espaços escolares e não escolares no Distrito Federal, objetivamos compreender a relação entre formação inicial e atuação. Uma das categorias desta investigação diz respeito ao papel da pesquisa na formação e na atuação deste profissional, cujos dados foram recolhidos por meio de questionário aplicado a 185 pedagogas(os) do Distrito Federal. A análise destes dados nos permitiu identificar que a pesquisa não está presente na formação e nem na atuação de pedagogas(os), seja na educação infantil e nos anos iniciais do ensino fundamental ou em espaços não escolares.

Dentre os sujeitos que participaram desta pesquisa há um grande número de pedagogas(os) que afirmam nunca terem participado de nenhuma atividade de pesquisa ou de grupos de pesquisa durante a formação, ou seja, não identificam nem a monografia realizada como Trabalho de Conclusão de Curso com a pesquisa, o que, para nós, é um dado bastante preocupante e que merece uma reflexão mais aprofundada, que tentaremos apresentar neste texto.

\section{Metodologia}

A pesquisa em educação nos coloca diante da natureza complexa do fenômeno educativo, daí a necessidade de compreendermos as múltiplas determinações que o compõem, ou seja, para poder explicar uma pequena parcela de tal fenômeno, é necessário conhecê-lo da forma mais completa possível, e não se pode chegar a esse conhecimento sem escolher um caminho.

É preciso eleger uma teoria que permita interpretar e explicar os fenômenos educativos, ou seja, é preciso um método. $\mathrm{A}(\mathrm{s})$ metodologia(s) e/ou técnica(s) escolhida(s) estão em consonância e 
ao mesmo tempo se subordinam ao método de investigação, uma vez que os dados obtidos por meio das técnicas deixam apenas entrever a realidade. A técnica não possui elementos que possam, por si mesmos, explicar a realidade, é preciso ter um método para expor essa realidade: o mérito de uma pesquisa é a capacidade do pesquisador para construir uma explicação da realidade investigada.

É, sem dúvida, necessário distinguir o método de exposição, formalmente, do método de pesquisa. A pesquisa tem de captar detalhadamente a matéria, analisar as suas várias formas de evolução e rastrear sua conexão íntima. Só depois de concluído esse trabalho é que se pode expor adequadamente o movimento do real (MARX, 1983, p. 20).

Nesse sentido, o método de análise/de exposição desta pesquisa é o materialismo histórico-dialético que, segundo Frigotto (1989, p. 77), não é uma ferramenta asséptica, "[...] uma espécie de metrologia dos fenômenos sociais, que nas perspectivas que denomino de metafísicas é tomada como garantia da cientificidade, da objetividade e da neutralidade", e que está presente em todo momento, desde o início da pesquisa, na definição do problema, na metodologia, na análise e na exposição desta análise.

$\mathrm{O}$ autor adverte que, na perspectiva materialista histórica, o método está vinculado a uma concepção de mundo e de vida em seu conjunto, ou seja, o método traduz, e porque não, explica, uma dada realidade: o método é mediação no processo de apreender, revelar e expor a estrutura, e o mais importante, as contradições dos fenômenos sociais.

A análise dos fenômenos educacionais é uma construção de teorias sobre suas manifestações mais simples e imediatas em relação com a totalidade social e histórica. E é o método que permite tal movimento do pensamento, o que certamente não é fácil, pois implica reconhecer, em relação ao objeto de pesquisa, que este se constitui nas relações sociais construídas pela humanidade durante todo tempo histórico (historicidade e totalidade); é a síntese de múltiplas determinações (contradição); e necessita ser analisada a partir das relações que os homens estabelecem com a realidade e entre si na produção e reprodução de sua existência (trabalho). 
De acordo com Pires (1997), estas são as categorias fundamentais a partir das quais se pode realizar uma análise materialista histórico-dialética de um determinado fenômeno social. A análise dos dados das pesquisas foi realizada no movimento de perceber e compreender, nas categorias fundamentais do método, as categorias que foram emergindo do objeto de estudo: formação, trabalho docente, teoria e prática, pesquisa.

Os procedimentos metodológicos empregados na investigação sobre a concepção de pesquisa dos professores da educação básica com formação stricto sensu, realizada no período de 2007 a 2009 em Goiânia, consistiu na proposição de um questionário com questões abertas e fechadas para 138 professores da educação básica. Destes, 91 foram devolvidos e 32 professores foram também entrevistados.

Para a realização da investigação sobre a formação e a atuação de pedagogas(os) em espaços escolares e não escolares, o procedimento metodológico utilizado até aqui é também o questionário, composto por 42 questões abertas e fechadas, dividido nos seguintes temas: perfil, formação, atuação profissional, políticas públicas e carreira. Após a análise dos questionários pretendemos dar início a uma segunda etapa de recolha de dados por meio de entrevistas.

A escolha pelo procedimento do questionário nas duas pesquisas é decorrente da objetividade na obtenção das informações, possibilitando interligar as diferentes informações de forma que uma questão afirme a outra ou mostre possíveis contradições, além da participação de um número maior de participantes para a pesquisa. Os questionários do tipo fechado "[...] buscam elementos da experiência que o sujeito possa expressar da forma direta” (GONZÁLEZ REY, 2005, p. 51) e o do tipo aberto "[...] permite a expressão do sujeito em trechos de informações que são objetos do trabalho interpretativo do pesquisador" (GONZÁLEZ REY, 2005, p. 51).

Em relação à pesquisa sobre a formação e atuação de pedagogas(os), a proposição dos questionários foi realizada no Distrito Federal, onde dividimos a coleta de dados em espaços escolares e não escolares. Os sujeitos participantes são profissionais formados no curso 
de Pedagogia que estão atuando no cargo de pedagogo em instituições públicas escolares e não escolares, localizadas aleatoriamente nas regiões administrativas do Distrito Federal.

Em aproximadamente dois meses, tivemos 185 questionários respondidos. Para análise dos resultados as questões foram primeiramente separadas entre os integrantes do grupo de pesquisa em duplas e trios, sendo depois discutidas e analisadas no grande grupo, no qual foram construídas categorias de análise, dentre as quais o papel da pesquisa na formação e na atuação de pedagogas(as), que detalharemos a seguir.

\section{A concepção de pesquisa dos professores da educação básica com formação stricto sensu}

Para o professor que está na escola pública em Goiânia e cursou um programa stricto sensu, ou seja, realizou uma pesquisa acadêmica, qual a concepção de pesquisa que prevalece? Foram vários os critérios definidores do que é uma pesquisa apontados pelos professores e percebemos concepções de pesquisa que não são muito precisas e que apresentam significações diferenciadas, como se pode observar na tabela a seguir:

Tabela 1 - Concepção de pesquisa dos professores da educação básica

(Continua)

\begin{tabular}{llc}
\hline \multicolumn{1}{c}{ Pesquisa é } & Freq. & $\%$ \\
\hline Buscar questões e respondê-las. & 28 & 30,7 \\
Buscar novas informações. & 19 & 21,0 \\
Controle de resultados, lógica, objetividade, rigor. & 10 & 11,0 \\
Explicação da realidade. & 09 & 9,8 \\
Elaboração teoria e prática. & 05 & 5,4 \\
Compreensão da realidade e intervenção. & 04 & 4,3 \\
\hline
\end{tabular}


Tabela 1 - Concepção de pesquisa dos professores da educação básica

(Conclusão)

\begin{tabular}{llc}
\hline \multicolumn{1}{c}{ Pesquisa é } & Freq. & $\%$ \\
\hline Produção do conhecimento. & 03 & 3,3 \\
Processo formativo. & 02 & 2,1 \\
Desvendar o conhecimento de forma sistemática e buscar soluções práticas & 05 & 5,4 \\
para o desempenho profissional. & & \\
Olhar e escuta observador. & 01 & 1,0 \\
Não respondeu. & 05 & 5,4 \\
Total & 91 & 100,0 \\
\hline
\end{tabular}

Fonte: Dados da pesquisa.

\section{Concepção de pesquisa dos professores da educação básica com formação stricto sensu}

Criamos três tipificações que indicam a concepção de pesquisa dos professores que participaram desta investigação. O primeiro tipo denominamos de pesquisa no sentido amplo, no qual os professores entendem a pesquisa como ato pelo qual se procura obter conhecimento sobre alguma coisa. É buscar informações, respostas, debruçar-se sobre algum problema para solucioná-lo, esclarecer dúvidas, aumentar o conhecimento, fazer escolhas. Como pode-se observar na tabela anterior, essa categoria contempla o maior número de repostas, com uma frequência de 47 respondentes $(51,7 \%)$ do total de 91 sujeitos.

Nessa concepção, aparece uma certa influência da formação stricto sensu pela amplitude da definição e a indicação de que pesquisar é buscar questões e respondê-las pode ser um aspecto decorrente do projeto de pesquisa desenvolvido no programa. Também parece não haver, nesse tipo de resposta, a influência das teorias sobre professor-reflexivo/ pesquisador, pois investigar ou pesquisar a prática não aparece como definição de uma pesquisa. 
Quanto à segunda tipificação, denominamos de pesquisa no sentido estrito (ciência). Está relacionada à criação de um corpo de conhecimentos sobre certo objeto, com características específicas; não se busca qualquer conhecimento, mas um conhecimento que ultrapassa a imediaticidade e o senso comum. Nesse caso, é a elaboração de ciência, ou seja, elaborar um conjunto estruturado de conhecimentos que permitam compreender em profundidade aquilo que à primeira vista não se compreende ou parece óbvio, utilizando critérios rigorosos, baseados em um método para construir uma compreensão aproximada do objeto.

Chamamos de pesquisa como estratégia pedagógica ou atitude reflexiva a terceira tipificação de pesquisa, que corresponde a uma concepção de pesquisa relacionada à atividade formativa; a uma atitude reflexiva, olhar e escutar a realidade com o objetivo de buscar soluções para a prática profissional do professor. Essa concepção parece estar relacionada com a perspectiva do professor-reflexivo, aproxima-se das ideias de Schön (2000) e vê a reflexão sobre os problemas da prática como metodologia.

Ao cruzar os dados do questionário com as entrevistas, percebe-se que os professores diferenciam a pesquisa no sentido estrito (ciência), a pesquisa acadêmica realizada em programas de mestrado e doutorado em universidades, da pesquisa em sentido amplo ou como estratégia pedagógica ou atitude reflexiva. Para os professores, a pesquisa acadêmica obedece a critérios rigorosos, próprios do campo científico, que não necessariamente devem ou precisam ser observados na pesquisa em sentido amplo ou na pesquisa como atitude reflexiva.

Essa diferenciação por vezes toma a pesquisa no sentido estrito (ciência), como uma pesquisa superior às outras, pois o acesso aos seus mecanismos de produção do conhecimento via programas de pós-graduação acaba ficando restrito a alguns poucos professores. Um aspecto interessante da concepção de pesquisa no sentido estrito (ciência) é a identificação da pesquisa acadêmica realizada nos programas de mestrado e doutorado com uma concepção positivista de produção do conhecimento.

É necessário enfatizar que a concepção de pesquisa no sentido estrito (ciência) não foi predominante entre os sujeitos: de um total de 30 
entrevistados, 19 professores demonstram uma concepção de pesquisa no sentido amplo, afirmam realizar pesquisa para buscar informações, a pesquisa que realizam tem como principal objetivo encontrar respostas que atendam às necessidades reais e imediatas do trabalho docente, revestida de caráter pragmático.

Há uma observação importante a ser feita diante dos dados da pesquisa: diferentemente do que imaginávamos, poucos professores apresentam uma concepção de pesquisa baseada na literatura sobre o professor-reflexivo/pesquisador, concepção que tem norteado boa parte da produção acadêmica nos cursos de pós-graduação stricto sensu e também as políticas e programas de formação de professores em nosso país. Nas poucas vezes em que aparece, essa concepção foi explicitada pelos sujeitos com diferentes entendimentos, predominando a ideia de "atitude investigativa" ou "atitude reflexiva", muito próxima da ideia de estudo. Alguns professores apontam ainda que esta "atitude investigativa" não é pesquisa, mas uma postura profissional, afirmando por vezes que esta não pode ser comparada à pesquisa no sentido estrito (ciência).

Por outro lado, há uma contradição interessante presente em muitas falas: os professores não percebem a pesquisa no sentido estrito (ciência) como atividade inerente ao trabalho docente, bem como há algumas afirmações de que a pesquisa no sentido estrito (ciência) não muda a prática. O caminho da reflexão, da postura investigativa e da observação é que poderia levar os professores a uma melhor compreensão da prática, sem que seja necessário rigor científico.

A pesquisa acadêmica ou pesquisa no sentido estrito (ciência) é entendida como aquela que tem rigor metodológico e base teórica e a pesquisa como atitude reflexiva, que busca informações e estratégias pedagógicas é considerada mais prática e rápida, capaz de responder às demandas imediatas da sala de aula, é uma pesquisa de "outro tipo", em que os professores identificam e hierarquizam as diferenças entre esta pesquisa e a acadêmica.

Em seu trabalho, André (2001) utiliza-se das classificações de Beillerot (2001) e Demo (1994) para refletir sobre tal questão, afirmando a necessidade de tentar identificar nas pesquisas dos professores que 
classificação ou tipo lhe cabe, podendo todas, no entanto, ser entendidas como pesquisa, não sendo necessário classificar a pesquisa dos professores na escola como de "outro tipo" (ANDRÉ 2001); André e Lüdke (1986), Stenhouse (1987) e Zeichner (1993) argumentam a favor dessa concepção: não se deve comparar a pesquisa do professor com a pesquisa acadêmica, mas ambas são pesquisas e não poderiam ser classificadas no sentido de "melhor/pior", "mais científica/menos científica".

Segundo a perspectiva do movimento do professor-reflexivo/ pesquisador, a preocupação com a cientificidade da pesquisa no cotidiano, ou seja, a preocupação em saber se o professor-pesquisador que investiga permanentemente a sua prática faz ciência é uma questão da academia. O professor, no cotidiano, não está fundamentalmente preocupado com a cientificidade de sua postura investigativa, mas com a sua efetiva capacidade de aprimorar a prática. No nosso entendimento, no entanto, adotar essa perspectiva de pesquisa na formação e no trabalho docente significa a impossibilidade de compreender teoricamente a realidade e pensar caminhos para transformá-la, levando o professor a reproduzir ideias já prontas e comprometendo a qualidade do seu trabalho e a possibilidade de autonomia e emancipação.

A compressão gramsciana da categoria intelectual nos leva a considerar o professor como aquele que realiza um trabalho intelectual e técnico, pois a natureza do trabalho docente traz a necessidade de produção e não apenas de reprodução de conhecimentos.

Quando indagados sobre que tipo de pesquisa realizam nas escolas, os professores respondem, em sua maioria, que estas pesquisas são relativas à prática cotidiana, entendendo a pesquisa como uma metodologia de realização das atividades inerentes do trabalho docente: busca de informações sobre os conteúdos específicos a serem ensinados aos alunos; busca em livros, revistas e sites da internet por novas metodologias, estratégias e atividades que possam auxiliar no trabalho em sala de aula; realização de levantamentos ou preparação de recursos e materiais didáticos existentes ou necessários; observação dos alunos; estudo de temáticas relacionadas à problemas de aprendizagem, indisciplina, inclusão e outros. 
Dois professores que exercem função técnica relatam na entrevista que desenvolvem uma pesquisa do tipo survey, no intuito de obter dados gerais sobre a rede, numa perspectiva avaliativa e quantitativa, a fim de ter elementos para propor ações no âmbito da secretaria em que atuam. Esses professores afirmam que a formação no programa stricto sensu foi essencial para que pudessem desenvolver esse tipo de pesquisa, pois adquiriram o domínio metodológico.

Quatro professores realizam o que chamaremos aqui de pesquisa de caratér voluntário, pois são descritas, pelos entrevistados, como iniciativas e/ou atitudes próprias. Alguns afirmam tentar observar os critérios da pesquisa acadêmica, mas salientam a dificuldade em conciliar o trabalho cotidiano com a pesquisa. Os objetos destas pesquisas nem sempre estão relacionadas aos problemas do cotidiano escolar, mas referem-se a temas e indagações de interesse particular do professor. Não queremos entrar no mérito da avaliação das pesquisas, se atingiram ou não seus objetivos, mas salientar que esses professores, após terminarem o curso de pós-graduação stricto sensu, estão tentando dar continuidade às suas pesquisas ou iniciar outra, enquanto trabalham na educação básica, o que consideramos bastante positivo.

Dois professores declararam estar desenvolvendo nas escolas pesquisas no sentido estrito (ciência), ligadas a instituições de ensino superior: uma pesquisa de doutorado e outra em decorrência das atividades do professor numa instituição de ensino superior. Os sujeitos desta pesquisa são todos professores da educação básica com formação stricto sensu e encontramos apenas um que afirma realizar uma pesquisa acadêmica na escola, ainda que esta seja ligada às suas atividades como docente numa instituição de ensino superior.

Por que os professores não fazem pesquisa na educação básica, uma vez que possuem a formação necessária para tal? Entendemos que são múltiplas as determinações para tal fato, mas, para nós, o principal motivo que afasta o professor que está na escola da pesquisa científica são as condições objetivas de trabalho: falta tempo, material, disponibilidade e apoio. 
Com formação e atuação na área de Ciências Naturais, duas professoras relataram fazer pesquisa como atividade metodológica de ensino, buscam utilizá-la como princípio educativo, solicitando a seus alunos pesquisas de estudo em diferentes fontes e a realização e descrição de experimentações.

Uma destas professoras relata como exemplo uma pesquisa em que busca conhecer o funcionamento do Centro de Atendimento Integrado à Saúde (Cais) na comunidade em que seus alunos estão inseridos. Em todos os procedimentos da pesquisa, mesmo na análise, houve a participação dos alunos. Entretanto, segundo a própria professora, esta pesquisa é um "fato isolado", tanto na escola quanto em sua vida profissional. Alega que não realizará outra atividade desta natureza em razão da dificuldade de conciliar a pesquisa com as demandas da sala de aula, além da falta de apoio da escola.

Como já mencionamos anteriormente, a maioria dos professores relata que faz pesquisa compreendendo-a no sentido da "atitude investigativa e/ou reflexiva” ou como metodologia para a realização das atividades inerentes ao trabalho docente. A realização deste tipo de pesquisa foi explicitada pelos sujeitos de diferentes maneiras, em que emerge uma afirmação que merece nossa atenção: a de que é a única forma de pesquisa possível de ser realizada na escola.

Agrupamos os relatos de dez professores que afirmam realizar este tipo de pesquisa, muito embora alguns tenham revelado uma certa indecisão para definir a atividade que realizam como pesquisa, em decorrência da própria experiência no curso de mestrado e/ou doutorado. Há, nos depoimentos, a compreensão da concepção de pesquisa como reflexão, busca, elaboração, planejamento e estudo, muito próximo da tipificação que denominamos de pesquisa no sentido amplo, mas com objetivos muito bem definidos e voltados para a resolução de algum problema da prática profissional, como por exemplo, levantamentos na internet; avaliação diagnóstica dos alunos (observação, sondagem, classificação); busca de textos para o planejamento de aulas e atividades. Para nós, esse tipo de atividade não caracteriza nem a pesquisa no sentido estrito (ciência) 
e nem a pesquisa conforme propõem a epistemologia da prática, ou do professor-pesquisador ou do professor-reflexivo.

O professor-reflexivo/pesquisador, segundo Schön (2000), Zeichner (1993), Stenhouse (1987) e André (2001) investiga as atividades docentes e não apenas busca meios para realizá-las ou torná-las mais dinâmicas. Tem por objetivo repensar sua prática, sua ação docente e seus saberes, visando a concretizar um processo de ensino-aprendizagem mais significativo para ele e para seus alunos. Conforme Zeichner (1993) existem alguns critérios de legitimidade das pesquisas desenvolvidas pelos professores que estão relacionadas à clareza da pesquisa: sistematização e articulação de ideias, a compreensão do pesquisador sobre seu trabalho e o critério da validade dialógica com seus pares, componentes que parecem não constar das atividades relatadas pelos professores como pesquisa.

Os relatos dos professores descrevem atividades que se constituem na natureza do trabalho docente e demonstram a competência, a seriedade e a ética desses profissionais ao exercerem seu trabalho, compreendendo-o também como trabalho intelectual que tem como objeto o ato pedagógico, entendendo que isso implica o estudo constante. Podemos entender tais atividades como uma atitude investigativa, de busca, de questionamento, importantíssimas para a atuação docente. Como exemplo, podemos citar as fichas de avaliação diagnóstica que um dos professores elaborou e às quais tivemos acesso. Tais fichas são de extrema qualidade e representam um grande avanço na concepção e na prática da avaliação deste professor, mas não é uma pesquisa, embora tenha sido necessária uma grande quantidade de estudo para sua elaboração e utilização.

A pedagogia de projetos é mencionada por cinco professores como o tipo de pesquisa que realizam na escola. Os depoimentos dos professores demonstram que os projetos se referem à elaboração de propostas didático-pedagógicas que objetivam a melhoria do processo de ensino e aprendizagem de uma determinada disciplina ou conteúdo. Entendemos que se trata de projetos de intervenção pedagógica e não de projetos de pesquisa, muito embora seja importante salientar a qualidade e a seriedade dos projetos que foram desenvolvidos, a que tivemos acesso. 
Entendemos que o projeto é também produção de conhecimento, pois os projetos aos quais tivemos acesso estavam teoricamente fundamentados e possuíam objetivos e metodologia cuidadosamente descritos. No entanto, para nós os projetos pedagógicos são proposições de atividades pedagógicas baseadas no conhecimento já elaborado sobre a Pedagogia de Projetos (DEWEY, 1978; HERNÁNDEZ, 1998; ZABALA, 2002) que visam a aprimorar o processo de ensino e aprendizagem e não pesquisa.

Finalmente, conforme Schön (2000), que usa da expressão "prática reflexiva" para se referir ao processo de reflexão do professor sobre sua própria prática, processo que se dá em dois níveis: a reflexão na ação e a reflexão sobre a reflexão na ação; destacamos dois depoimentos em que os professores definiram como pesquisa seu processo de reflexão sobre a própria prática.

Um dos professores, por exemplo, vê o conselho de classe como pesquisa no sentido da prática reflexiva, pois considera que se trata de uma atividade investigativa, pois levanta questionamentos e leva o conjunto de professores à reflexão sobre os aspectos positivos e negativos do trabalho pedagógico e sobre as dificuldades e problemas da escola, bem como são levantadas opiniões, sugestões e encaminhamentos, além de comumente serem estudados textos teóricos sobre os principais problemas enfrentados na escola. Apesar da compreensão bastante interessante deste professor sobre a atividade de conselho de classe, é preciso salientar que nem toda prática reflexiva constitui-se em pesquisa no sentido de produzir conhecimentos, conforme Zeichner (1993) e Schön (2000).

\section{A pesquisa na formação e na atuação de pedagogas(os) em espaços escolares e não escolares}

Em relação ao papel da pesquisa na formação e atuação de pedagogas(os), no questionário aplicado a 185 profissionais de instituições públicas escolares e não escolares do Distrito Federal, a pesquisa é abordada no item que refere-se ao processo formativo, e indaga aos 
participantes quais atividades de pesquisa desenvolveram e/ou participaram durante o curso de Pedagogia e na atuação profissional, questionando se desenvolvem alguma pesquisa e que tipo de pesquisa desenvolvem em seu trabalho.

A análise das respostas nos permite identificar a quase que completa ausência da pesquisa tanto na formação quanto na atuação das (dos) pedagogas(os). Essa análise deve-se a diferentes fatores observados no conjunto das respostas:

a) houve um número muito baixo de respondentes para as questões sobre a pesquisa - de 185 respondentes apenas 37 deram respostas sobre a temática, 148 sujeitos deixaram as questões sobre a pesquisa em branco;

b) dos 37 sujeitos que responderam às questões sobre a pesquisa na formação e na atuação, todos afirmam que não desenvolvem pesquisa na sua atuação enquanto professores da educação infantil ou dos anos iniciais do ensino fundamental ou como profissionais que trabalham em espaços não escolares;

c) cinco sujeitos afirmam ter realizado ou estar realizando cursos de pós-graduação stricto sensu, relacionando essa formação à pesquisa;

d) um número considerável de respondentes parece não compreender o que é um grupo de pesquisa;

e) um número considerável de respondentes não associa a monografia realizada no Trabalho de Conclusão de Curso com a pesquisa.

Embora os estudos sobre formação de professores vêm apontando a pesquisa no processo educativo como elemento formativo do sujeito, sendo de fundamental importância para uma ação pedagógica que possibilite a relação teoria e prática e permita o sujeito-professor se conscientizar da realidade em que está inserido, percebe-se pelos dados que na formação inicial tal movimento é ainda incipiente e podendo dizer que não existe formação para a pesquisa. 
Não viver a pesquisa na formação inicial é um prejuízo na formação do professor, pois a pesquisa além de ser um ato educativo, reflexivo e formativo, é um ato político; pode e deve ser uma ação norteadora e incentivadora dentro e fora da instituição escolar. Os procedimentos que envolvem a realização das pesquisas possibilitam diferentes momentos para a problematização e a busca de conhecimentos e suas interfaces construíndo e transformando com criticidade, ética e coerência a ação de professores e alunos pesquisadores.

\section{Considerações finais}

Acreditamos que a pesquisa é fundamental no processo de formação e no trabalho dos professores da educação básica, pois na possibilidade da práxis e na recusa de ser homem-massa está a possibilidade de formação de sujeitos autônomos, capazes de resistência e de tomar suas próprias decisões. A pesquisa proporciona um esclarecimento que permite desvelar a superfície da realidade, das políticas e das práticas sociais aparentemente naturalizadas e cristalizadas. Isso significa que na pesquisa está também a possibilidade da emancipação humana e da transformação da realidade.

No entanto, é preciso ter clara qual a concepção de pesquisa que deverá nortear a formação inicial e as políticas de formação continuada e de valorização do magistério, pois ser um pesquisador não é partir em busca do acúmulo de conhecimentos e informações sobre uma determinada temática ou um problema enfrentado na escola. Reafirmamos aqui o compromisso das instituições formadoras e das políticas públicas de formação: tornar os profissionais da educação "sujeitos de conhecimento" capazes de apreender, analisar, criticar e produzir conhecimentos sobre seu trabalho.

Nesse sentido, a pesquisa já desenvolvida e a que se encontra em desenvolvimento no GEPFAPe pretende inserir-se no espaço de discussão aberto no campo da formação de professores e das políticas públicas, que compreende os professores e pedagogas(os) como profissionais capazes não apenas de refletir, mas de produzir conhecimentos sobre seu trabalho. 


\section{Referências}

ANDRÉ, M. Pesquisa em educação: buscando rigor e qualidade. Cadernos de Pesquisa, n. 113, p. 51-64, 2001.

ANDRÉ, M. (Org.). 0 papel da pesquisa na formação e na prática dos professores. 4. ed. Campinas: Papirus, 2005.

BEILLEROT, J. A pesquisa: esboço de uma análise. In: ANDRÉ, A. (Org.). O papel da pesquisa na formação e na prática dos professores. Campinas: Papirus, 2001. p. 71-90.

DEMO, P. Pesquisa e construção do conhecimento. Rio de Janeiro: Tempo Brasileiro, 1994.

DEWEY, J. Experiência e educação. São Paulo: EPU, 1978.

FRIGOTTO, G. A produtividade da escola improdutiva. São Paulo: Cortez, 1989.

GONZÁLEZ REY, F. (Org.). Subjetividade, complexidade e pesquisa psicológica. São Paulo: Pioneira, 2005.

HERNÁNDEZ, F. Transgressão e mudança na educação: os projetos de trabalho. Porto Alegre: Artmed, 1998.

LÜDKE, M.; ANDRÉ, M. Pesquisa em educação: abordagens qualitativas. São Paulo: EPU, 1986.

MARX, K. O Capital: crítica da economia política. São Paulo: Abril Cultural. 1983. Tomo 1.

MORAES, M. M. Sentidos do ser docente e da construção de seu conhecimento. In: MORAES, M. M. (Org.). Iluminismo às avessas: produção do conhecimento e políticas de formação docente. Rio de Janeiro: DP\&A, 2003. p. 45-60.

PIRES, M. F. C. O materialismo histórico-dialético e a educação. InterfaceComunicação, Saúde, Educação, v. 1, n. 1, p. 83-94, 1997. 
SCHÖN, D. Educando o profissional reflexivo. Porto Alegre: Artes Médicas, 2000.

STENHOUSE, L. la investigación como base de la enseñaza. Madri: Morata, 1987.

ZABALA, A. Enfoque globalizador e pensamento complexo. Porto Alegre: Artmed, 2002.

ZEICHNER, K. M. A formação reflexiva de professores: ideias e práticas. Lisboa: Educa, 1993.

Recebido: 29/05/2012

Received: 05/29/2012

Aprovado: 30/07/2012

Approved: 07/30/2012 